\title{
Ductile Cast Iron with High Toughness at Low Temperatures
}

\author{
Stephanie Duwe ${ }^{1, a^{*}}$ and Babette Tonn ${ }^{1, b}$
}

${ }^{1}$ Clausthal University of Technology - Institute of Metallurgy, Robert-Koch-Str. 42, 38678 Clausthal-Zellerfeld, Germany

aStephanie.Duwe@tu-clausthal.de, 'Babette.Tonn@tu-clausthal.de

\section{Keywords: DI, DoE, alloy design}

\begin{abstract}
High life expectancy of cast components and good material performance at dynamic load are a prerequisite to cater for future trends in wind energy generators. To remain competitive in this ever evolving sector challenges reside in alloy development. In this work fractional factorial design has been applied to ferritic ductile iron with varying contents of silicon (1.6-2 wt $\%)$, nickel (0-1 wt $\%)$, cobalt $(0-3 \mathrm{wt} \%)$ and copper $(0-0.2 \mathrm{wt} \%)$. The minimum criteria the new alloy should meet were a minimum yield strength of $240 \mathrm{MPa}$ and an impact work of minimal $8 \mathrm{~J}$ at a temperature of $-20{ }^{\circ} \mathrm{C}$ for wall thicknesses of $60-200 \mathrm{~mm}$. To obtain these mechanical properties thick-walled castings with additional insulation were produced to achieve a higher thermic module. They provided the material for test specimens to perform static tensile tests, Charpy impact tests at varying temperatures and a microstructure analysis. With these results, a sweet spot plot has been created. That way, an optimum alloy composition could be found and has been proven by validation experiment.

The optimum alloy for thick-walled castings is composed of $\mathrm{Si}=1.6 \mathrm{wt} \%, \mathrm{Cu}=0.2 \mathrm{wt} \%$, $\mathrm{Ni}=0 \mathrm{wt} \%$ and $\mathrm{Co}=0 \mathrm{wt} \%$. It offers an enhancement in yield strength and acceptable impact work at low temperatures for massive castings in as cast state. The heat treated, full ferritic material could even improve these results.
\end{abstract}

\section{Introduction}

Technological progress in renewable energies in the field of ultra large wind generators in regions of unpredictable and/or very low temperatures demand ductile iron (DI) with advanced qualities. To guarantee a high life expectancy of cast components this alloy development focuses on good material performance at dynamic load. High strength accompanied by high toughness even at low temperatures is needed. The technical standard EN 1563:2011 provides only two ferritic materials with ductile fracture at low temperatures: EN-GJS-400-18 LT and EN-GJS-350-22-LT, but both lack sufficient strength in massive castings. The properties of EN-GJS-400-18 LT form the groundwork in this research. On this basis, minimum criteria the new alloy should meet are a yield strength of $240 \mathrm{MPa}$ and an impact work of $8 \mathrm{~J}$ at a temperature of $-20{ }^{\circ} \mathrm{C}$ for wall thicknesses of 60-200 mm.

The aim of this alloy development is an increase in strength accompanied by high toughness at low temperatures which means the transition region obtained by impact tests at varying temperatures must be shifted to temperatures lower than $-20^{\circ} \mathrm{C}$, better $-40^{\circ} \mathrm{C}$. An optimum between high strength and high toughness at low temperatures must be found.

To influence the mechanical properties of an alloy the impact of each selected element on the microstructure of the ductile iron has to be identified. Silicon, copper, nickel and cobalt were chosen as most promising for the desired properties. The basis of our decision-making can be found in previous research:

In thick-walled castings with restrained cooling rates the eutectoid reaction predominantly follows the stable system which yields a primarily ferritic structure. In this regard the graphite distribution has a great influence as it defines the diffusion length of carbon which has a direct impact on the ferrite/pearlite ratio [1,2]. This impact is particularly high if the nodule count is low $[2,3]$. All elements investigated in this research $(\mathrm{Si}, \mathrm{Cu}, \mathrm{Ni}, \mathrm{Co})$ have the effect to expand the 
temperature interval of stable solidification (with decreasing effect, $\mathrm{dT}(\mathrm{Si})=35 \mathrm{~K}$ [4]) and promote the graphitisation $[5,6]$.

An increase in nodule count up to 500 particles leads to higher impact work, followed by a decrease (in thin-walled castings) [7]. The smaller the nodules are the higher is their nodularity which leads to an increase in tensile strength, elongation, fracture toughness and resistance to crack propagation [8-10].

Silicon increases the carbon activity which leads to a solubility decrease of carbon in austenite that promotes graphite crystallisation during stable solidification $[1,11]$ and in turn yields an enhancement in ferrite formation during the eutectoid reaction [1] as the ferritic transformation interval is widened [6]. According to [12] silicon shows one of the highest solid solution hardening effects in iron. In addition silicon to some degree increases copper solubility in ferrite [4]. Copper improves the graphitisation 0.2-0.3 times as much as silicon, so it cannot substitute the silicon but it can support the graphitisation effect of silicon and at the same time neutralise the effect of carbidepromoting elements [4]. Copper is known to depress the stable eutectoid temperature and to restrain carbon diffusion in austenite which yields in formation of pearlite $[4,13]$. On the other hand, low contents of copper $(<0.6 \mathrm{wt} \%)$ showed no significant pearlite promoting effect at low cooling rates $[3,14]$. This is related to the maximum copper solubility of $0.6 \mathrm{wt} \%$ in ferrite [4]. However, precipitation hardening of ferrite caused by copper starts at a mass fraction of $0.4 \%$ [12]. Since copper content levels at maximum $0.2 \mathrm{wt} \%$ in this research copper cannot be considered neither as a pearlite promoter nor as precipitation hardening element. On the other hand, the copper-induced solid solution hardening of ferrite is taken into account which already starts with small additions and is of the same magnitude as the silicon-induced solid solution hardening [12].

Nickel stabilises austenite by lowering the eutectoid reaction temperature to such an extent that the carbon diffusion is well retarded to turn austenite directly into pearlite $[1,11]$. It also increases copper solubility in austenite [4, 11]. DI alloying contents up to $1 \mathrm{wt} \% \mathrm{Ni}$ or $0.45 \mathrm{wt} \% \mathrm{Cu}$ were investigated and identified to decrease the upper shelf of impact work as they harden and embrittle the ferrite $[15,16]$. At the same time, up to $0.18 \mathrm{wt} \% \mathrm{Cu}$ reduce the impact transition temperature, with higher contents or nickel addition no shift is detected [16].

According to [17] cobalt shows ferrite promoting tendencies already with small additions of $1 \mathrm{wt} \%$. In [18] the influence of a large variety of elements on "interstitial-free" iron was investigated. For the present work their impact on ferrite can be derived. Cobalt and nickel (1.5-3 wt $\%$ ) both show good solubility in iron but whereas nickel has a considerable positive effect on solid solution hardening - which drops after a maximum at ambient towards low temperatures cobalt can resume the strengthening from there on. So, cobalt is needed for the low temperature region. Both elements lead to an increase in toughness when alloyed (nickel much more than cobalt) accompanied by a decrease of transition temperature provoked by nickel and an increase induced by cobalt additions [18]. By addition of $4 \mathrm{wt} \%$ Co nodule count and thus, ferrite content can be increased. The same amount of nickel causes the complete opposite. Both provide an increase in tensile and yield strength as well as a decrease in elongation compared to an unalloyed ductile iron. However, cobalt increases toughness whereas nickel lowers it in favour of a gain in hardness promoted by a high pearlite content (75\%) [19]. This does not contrast with the findings from [18] as ferrite is regarded there exclusively. The improvement of yield strength and impact toughness with cobalt is induced by hardening of ferrite. Nevertheless, it increases the transition temperature and lowers the low temperature toughness [17].

From [20] it can be derived that the maximum alloying contents of elements in the present work $(0.2 \mathrm{wt} \% \mathrm{Cu}, 3 \mathrm{wt} \% \mathrm{Ni}, 1 \mathrm{wt} \% \mathrm{Co})$ at $2-2.2 \mathrm{wt} \% \mathrm{Si}$ provoke an increase of yield strength with nickel (followed by copper, no effect caused by cobalt).

\section{Experimental}

The spectrum of elements to vary has been chosen using fractional factorial design of experiments (DoE). As a result, elements are applied in the range of $1.6-2.0 \mathrm{wt} \% \mathrm{Si}, 0.0-0.2 \mathrm{wt} \%$ $\mathrm{Cu}, 0.0-1.0 \mathrm{wt} \% \mathrm{Ni}$, and $0.0-3.0 \mathrm{wt} \% \mathrm{Co}$ respectively. The carbon content is calculated at a 
saturation of $\mathrm{Sc}=1$ by $[\mathrm{wt} \% \mathrm{C}]=4.26-1 / 3[\mathrm{wt} \% \mathrm{Si}]$ and the final magnesium content should be $0.04 \pm 0.01 \%$. Inoculation $(0.3 \mathrm{wt} \%)$ and melt treatment (corresponding to sulphur) are performed without cerium. An overview of the alloying composition gives Table 1.

Table 1: Target compositions of alloys N1-11

\begin{tabular}{|c|c|c|c|c|c|c|c|c|c|c|c|}
\hline $\begin{array}{ll}\text { element } & \text { alloy }\end{array}$ & N1 & $\mathrm{N} 2$ & N3 & N4 & N5 & $\begin{array}{c}\mathrm{N} 6 \\
\mathrm{wt} \%\end{array}$ & N7 & N8 & N9 & N10 & N11 \\
\hline $\mathrm{Si}$ & 1.6 & 2.0 & 1.6 & 2.0 & 1.6 & 2.0 & 1.6 & 2.0 & 1.8 & 1.8 & 1.8 \\
\hline $\mathrm{Cu}$ & 0.0 & 0.2 & 0.2 & 0.0 & 0.2 & 0.0 & 0.0 & 0.2 & 0.1 & 0.1 & 0.1 \\
\hline $\mathrm{Ni}$ & 0.0 & 0.0 & 0.0 & 0.0 & 1.0 & 1.0 & 1.0 & 1.0 & 0.5 & 0.5 & 0.5 \\
\hline Co & 0.0 & 0.0 & 3.0 & 3.0 & 0.0 & 0.0 & 3.0 & 3.0 & 1.5 & 1.5 & 1.5 \\
\hline
\end{tabular}

The melts consisting of $70 \%$ pig iron and $30 \%$ DC04 steel of drawing grade is prepared in an induction furnace. Alloying is done at $1400^{\circ} \mathrm{C}$. Then the melt is heated to $1500{ }^{\circ} \mathrm{C}$. The subsequent magnesium treatment (sandwich process) is performed in a preheated ladle $\left(950{ }^{\circ} \mathrm{C}\right)$. After deslagging the melt is inoculated and cast into furan resin bound Y4 moulds with additional insulation for a higher thermic module to simulate particularly thick-walled castings. In addition, the identified optimum composition is cast separately under equal conditions to validate the DoE results. The chemical composition of raw materials is listed in Table 2.

Table 2: Chemical composition of raw materials

\begin{tabular}{|c|c|c|c|c|c|c|c|c|c|c|c|c|c|}
\hline & $\mathrm{Al}$ & $\mathrm{Ba}$ & $\mathrm{C}$ & $\mathrm{Ca}$ & $\mathrm{Ce}$ & $\mathrm{La}$ & $\begin{array}{c}\mathrm{wt}^{\%} \\
\mathrm{Mg}\end{array}$ & $\mathrm{Mn}$ & $\mathrm{P}$ & $\mathrm{S}$ & $\mathrm{Si}$ & $\mathrm{Sr}$ & $\mathrm{Ti}$ \\
\hline Mg master alloy & 0.76 & 0.01 & - & 1.74 & 0.07 & 0.05 & 6.03 & 0.30 & 0.01 & 0.01 & 44.8 & 0.00 & 0.05 \\
\hline inoculant & 1.07 & 1.95 & - & 1.71 & 0.01 & 0.00 & 0.03 & 0.19 & 0.01 & 0.02 & 71.9 & 0.10 & 0.07 \\
\hline pig iron & 0.01 & - & 3.87 & - & 0 & 0 & 0 & 0.01 & 0.01 & 0.01 & 0.80 & - & 0.01 \\
\hline $\mathrm{DC} 04$ & 0.04 & - & 0.00 & 0 & 0 & 0 & - & 0.10 & 0.01 & 0.01 & 0.02 & - & 0.08 \\
\hline
\end{tabular}

Following the inoculation and prior to casting small samples cast into a copper mould are taken for the chemical analysis. The wet chemical analysis is done by optical emission spectroscopy with inductively coupled plasma (ICP-OES). The carbon content is drawn from combustion analysis.

After cooling down to ambient temperature the gating system and feeders are cut away and samples are prepared from the remaining volumes. They are used for tensile testing (DIN EN ISO 6892-1 type B) and V-notched impact testing (DIN EN ISO 148-1) at $-20{ }^{\circ} \mathrm{C}$. From the impacted specimens a microstructure analysis (DIN EN ISO 945 - part 2) is done by visual particle analysis (polished samples) and a grey scale analysis of ferrite/pearlite ratio (Nital-etched samples).

A selection of samples is heat treated at $750{ }^{\circ} \mathrm{C}$ for 13 hours with subsequent oven cooldown to obtain full ferritic specimens for tensile and impact tests as well as microscopic analysis.

\section{Results}

The chemical analysis of all alloys is in good agreement with those the DoE demanded. An overview of all alloy compositions gives Table 3 .

Table 3: Chemical composition of alloys N1-11 from ICP-OES

\begin{tabular}{|c|c|c|c|c|c|c|c|c|c|c|c|}
\hline element alloy & N1 & N2 & N3 & N4 & N5 & $\begin{array}{c}\mathrm{N} 6 \\
\mathrm{wt}[\%\end{array}$ & N7 & N8 & N9 & N10 & N11 \\
\hline $\mathrm{Si}$ & 1.67 & 2.11 & 1.56 & 2.06 & 1.54 & 2.09 & 1.62 & 2.12 & 1.84 & 1.79 & 1.82 \\
\hline $\mathrm{Cu}$ & 0.02 & 0.23 & 0.21 & 0.02 & 0.23 & 0.03 & 0.02 & 0.23 & 0.11 & 0.11 & 0.11 \\
\hline $\mathrm{Ni}$ & 0.06 & 0.06 & 0.06 & 0.06 & 0.98 & 0.96 & 0.97 & 1.00 & 0.49 & 0.48 & 0.47 \\
\hline Co & 0.02 & 0.03 & 2.99 & 3.12 & 0.03 & 0.03 & 3.11 & 3.14 & 1.51 & 1.48 & 1.50 \\
\hline$C^{*}$ & 3.73 & 3.69 & 3.75 & 3.63 & 3.73 & 3.65 & 3.63 & 3.61 & 3.70 & 3.74 & 3.72 \\
\hline $\mathrm{Mg}$ & 0.04 & 0.04 & 0.05 & 0.04 & 0.04 & 0.04 & 0.05 & 0.05 & 0.04 & 0.05 & 0.05 \\
\hline
\end{tabular}

Table 4 gives an overview of the results from mechanical testing and microscopic analysis. 
Table 4: Yield strength (Rp0.2), impact work at $-20{ }^{\circ} \mathrm{C}\left(\mathrm{Wt}\left(-20{ }^{\circ} \mathrm{C}\right)\right)$ and ferrite/pearlite content of alloys N1-11 in as cast and ferritic state

\begin{tabular}{|c|c|c|c|c|c|c|}
\hline alloy & $\begin{array}{c}\mathrm{R}_{\mathrm{p} 0.2} \\
{[\mathrm{MPa}]}\end{array}$ & $\begin{array}{r}\text { as cast } \\
\mathrm{W}_{\mathrm{t}}\left(-20{ }^{\circ} \mathrm{C}\right) \\
{[\mathrm{J}]}\end{array}$ & $\begin{array}{c}\text { ferrite/pearlite } \\
{[\%]}\end{array}$ & $\begin{array}{c}\mathrm{R}_{\mathrm{p} 0.2} \\
{[\mathrm{MPa}]}\end{array}$ & $\begin{array}{r}\text { ferritic } \\
\mathrm{W}_{\mathrm{t}}\left(-20^{\circ} \mathrm{C}\right) \\
{[\mathrm{J}]}\end{array}$ & $\begin{array}{c}\text { ferrite/pearlite } \\
{[\%]}\end{array}$ \\
\hline N1 & $274 \pm 16$ & $5.3 \pm 3.5$ & $48.5 / 51.5$ & $222 \pm 5$ & $12.0 \pm 1.0$ & $95.9 / 4.1$ \\
\hline $\mathrm{N} 2$ & $287 \pm 14$ & $7.0 \pm 4.4$ & $74.8 / 25.2$ & $251 \pm 3$ & $13.0 \pm 1.0$ & $97.2 / 2.8$ \\
\hline N3 & $260 \pm 13$ & $7.7 \pm 2.1$ & $72.8 / 27.2$ & $229 \pm 1$ & $14.0 \pm 1.7$ & $89.7 / 10.3$ \\
\hline N4 & $277 \pm 5$ & $4.0 \pm 1.0$ & $89.3 / 10.7$ & $263 \pm 2$ & $5.7 \pm 0.6$ & $90.6 / 9.4$ \\
\hline N5 & $311 \pm 4$ & $5.3 \pm 2.5$ & $39.1 / 60.9$ & $259 \pm 4$ & $11.3 \pm 1.2$ & $90.7 / 9.3$ \\
\hline N6 & $310 \pm 11$ & $4.3 \pm 2.3$ & $78.0 / 22.0$ & $283 \pm 1$ & $8.7 \pm 1.2$ & $90.3 / 9.7$ \\
\hline N7 & $310 \pm 12$ & $4.0 \pm 1.7$ & $63.3 / 36.7$ & $266 \pm 1$ & $7.7 \pm 0.6$ & $93.2 / 6.8$ \\
\hline N8 & $342 \pm 2$ & $2.5 \pm 1.4$ & $65.2 / 34.8$ & $315 \pm 1$ & $4.3 \pm 1.5$ & $96.1 / 3.9$ \\
\hline N9 & $290 \pm 14$ & $7.0 \pm 3.5$ & $78.0 / 22.0$ & $255 \pm 1$ & $9.7 \pm 0.6$ & $95.8 / 4.2$ \\
\hline N10 & $283 \pm 15$ & $5.7 \pm 2.1$ & $78.0 / 22.0$ & $251 \pm 3$ & $11.3 \pm 1.2$ & $93.3 / 6.7$ \\
\hline N11 & $276 \pm 17$ & $8.0 \pm 5.7$ & 73.9 / 26.1 & $247 \pm 0$ & $14.3 \pm 1.5$ & $94.3 / 5.7$ \\
\hline
\end{tabular}

\section{Discussion}

The results received from the analyses were filled into the DoE as responses of the varied elements. The fractional factorial design shows the mechanical properties as a function of element content in a linear interpolation approach (see Fig. 1). With this model prognosis alloy properties of new compositions could become predictable but the linear approach does not cover the physical background of the connection between elements, microstructure and mechanical properties.

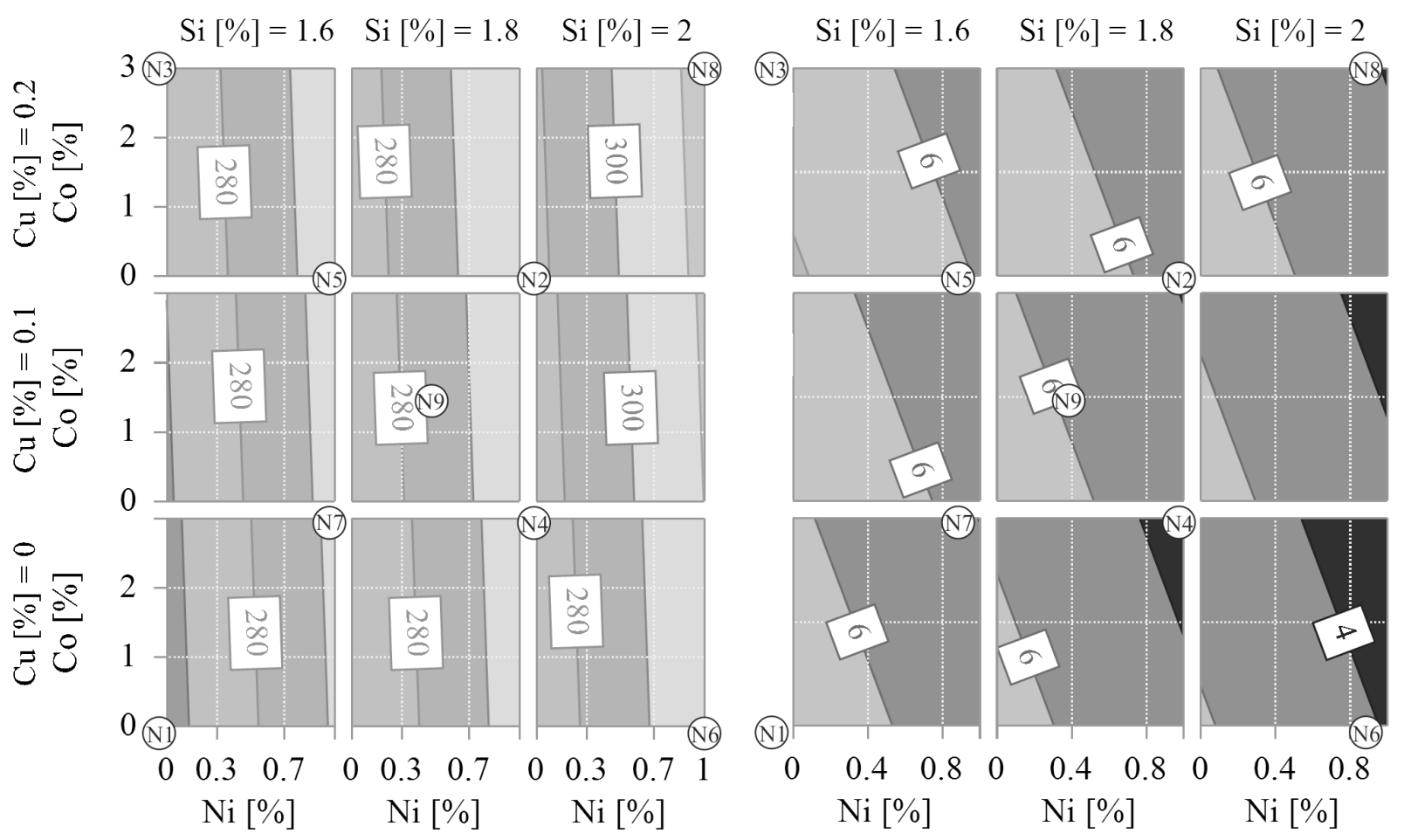

Figure 1: Linear interpolation approach of yield strength (left) and impact work at $-20{ }^{\circ} \mathrm{C}$ (right) as a function of $\mathrm{Si}, \mathrm{Cu}, \mathrm{Ni}$ and $\mathrm{Co}$ content

To receive an authoritative forecast from this interaction of factors (elements) and responses (mechanical results) the findings from literature must be considered concerning the influences of the elements on the DI structure. This means that if one element has no influence on the property considered it is removed from the interpolation equation (e.g. cobalt has no influence on yield strength at ambient temperature). When two elements complement one another a multiplication term is inserted into the equation (e.g. $\mathrm{Ni} \cdot \mathrm{Cu}$ as they promote each other's solubility). This leads to the following factor combination for the yield strength and impact work with model validity $\mathrm{R}^{2}$ and model prognosis Q2 given in Table 5. 
Table 5: Combination factors (elements) used (x) or neglected (-) for the interpolation approach

\begin{tabular}{lccccccccc}
\hline & state & $\mathrm{Si}$ & $\mathrm{Cu}$ & $\mathrm{Ni}$ & $\mathrm{Co}$ & $\mathrm{Ni} \cdot \mathrm{Cu}$ & $\mathrm{Co} \cdot \mathrm{Co}$ & $\mathrm{R}^{2}$ & $\mathrm{Q} 2$ \\
\hline $\mathrm{R}_{\mathrm{p} 0.2}$ & as cast & $\mathrm{x}$ & $\mathrm{x}$ & $\mathrm{x}$ & - & $\mathrm{x}$ & - & 0,90 & 0,59 \\
$\mathrm{R}_{\mathrm{p} 0.2}$ & ferritic & $\mathrm{x}$ & $\mathrm{x}$ & $\mathrm{x}$ & - & $\mathrm{x}$ & - & 0,92 & 0,54 \\
$\mathrm{~W}_{\mathrm{t}}\left(-20^{\circ} \mathrm{C}\right)$ & as cast & $\mathrm{x}$ & $\mathrm{x}$ & $\mathrm{x}$ & $\mathrm{x}$ & $\mathrm{x}$ & $\mathrm{x}$ & 0,90 & 0,60 \\
$\mathrm{~W}_{\mathrm{t}}\left(-20^{\circ} \mathrm{C}\right)$ & ferritic & $\mathrm{x}$ & $\mathrm{x}$ & $\mathrm{x}$ & $\mathrm{x}$ & $\mathrm{x}$ & $\mathrm{x}$ & 0,90 & 0,70 \\
\hline
\end{tabular}

It must be noted that for ambient temperature cobalt has only little influence on impact work but because of its significant strengthening at low temperatures it must be considered for the low temperature toughness. The $\mathrm{Ni} \cdot \mathrm{Cu}$ term stands for the mutual promoting effect of these elements concerning solubility and solid solution hardening. In addition the model for yield strength could be corrected by a $\mathrm{Cu} \cdot \mathrm{Cu}$, term like [21] did, but then the Q2 model prognosis would turn negative.

After filling the modified factor combination into the model, the following diagrams of interaction between elements and mechanical properties based on physical background are created (see Fig. 2).
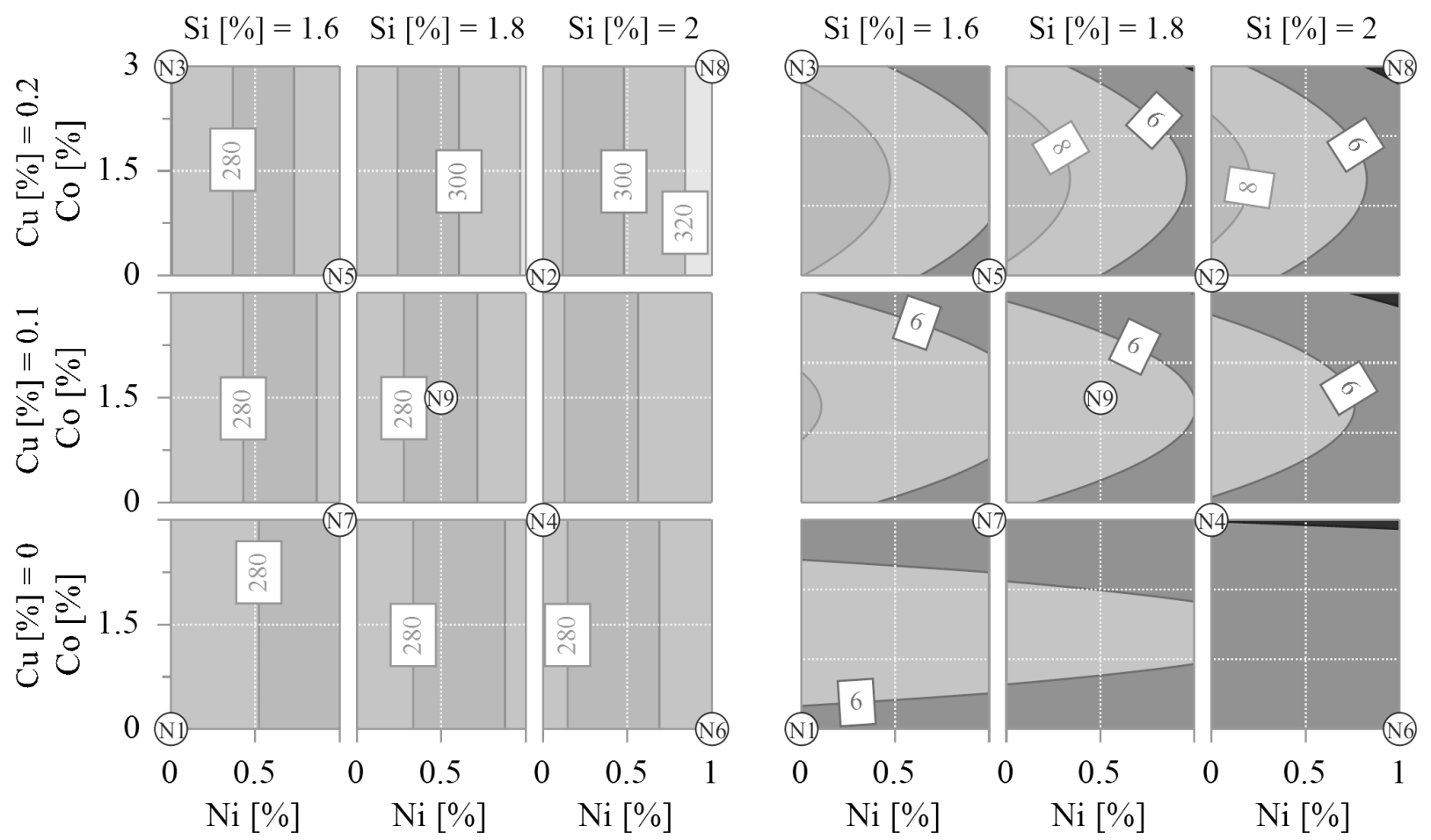

Figure 2: Modified interpolation approach of yield strength (left) and impact work at $-20{ }^{\circ} \mathrm{C}$ (right) in as cast state as a function of $\mathrm{Si}, \mathrm{Cu}, \mathrm{Ni}$ and $\mathrm{Co}$ content

For yield strength, the removal of cobalt influence is reflected in the now horizontal gradient as this element is only considered regarding low temperature properties and can be neglected elsewhere. By insertion of the quadratic cobalt term for the low temperature ferritic strengthening the impact work changes into a curved interdependency.

To find the optimum where all conditions stated at the beginning are fulfilled $\left(\mathrm{R}_{\mathrm{p} 0.2}>240 \mathrm{MPa}\right.$, $\left.\mathrm{W}_{\mathrm{t}}\left(-20^{\circ} \mathrm{C}\right) \geq 8 \mathrm{~J}\right)$ a sweet spot plot is created from the modified interpolation approach which is depicted in Fig. 3. The optimum element compositions are illustrated in light grey. The biggest process window opens at $1.6 \% \mathrm{Si}$ and $0.2 \% \mathrm{Cu}$ between $0-2.5 \% \mathrm{Co}$ and up to $0.4 \% \mathrm{Ni}$, depending on the cobalt content. Higher ratios of silicon are also possible but with lower nickel content. The copper content can also be reduced but it narrows the process window strongly. In the dark fields, the condition of $\mathrm{W}_{\mathrm{t}}>8 \mathrm{~J}$ is not fulfilled. 


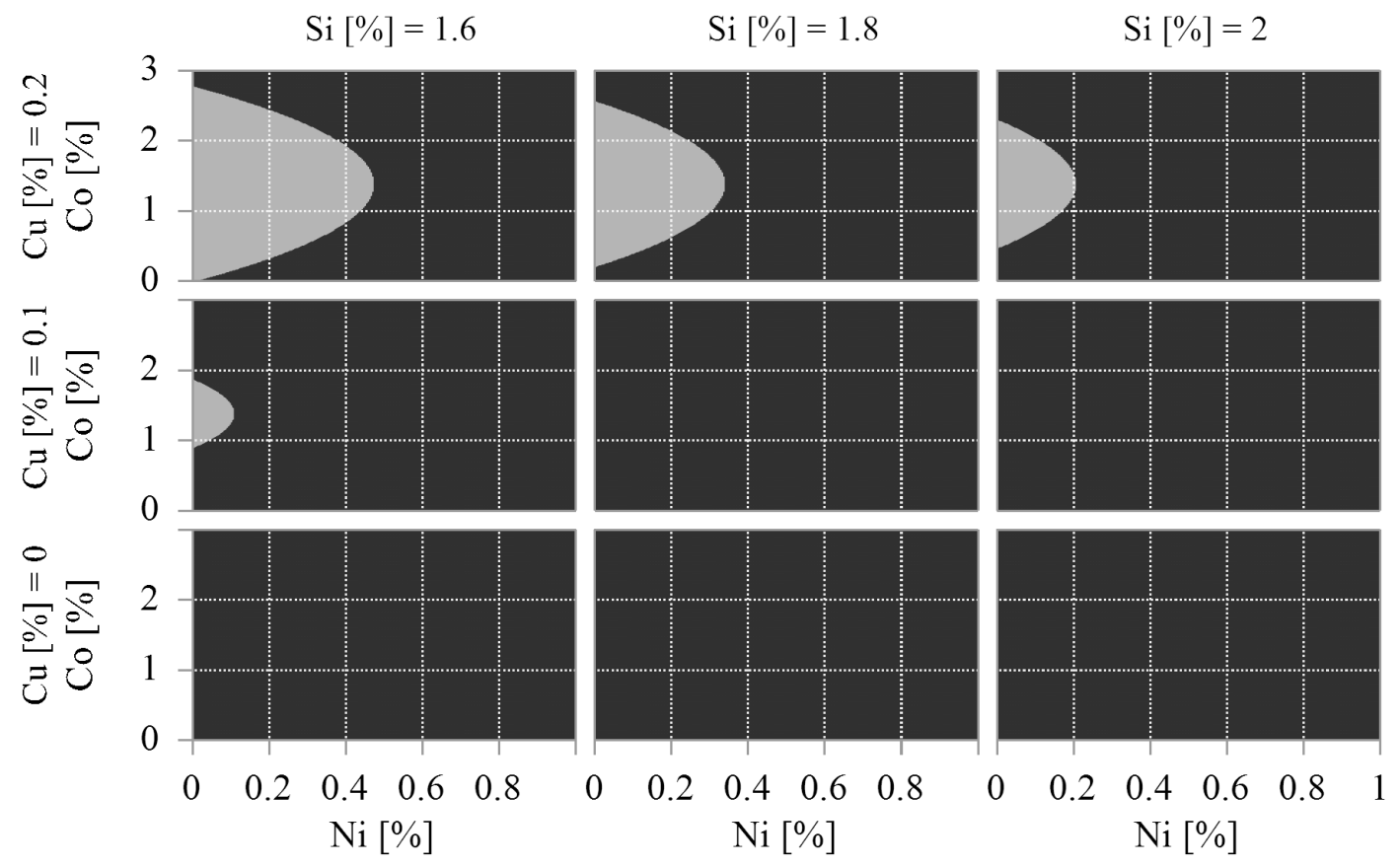

Figure 3: Sweet spot plot of yield strength $(>240 \mathrm{MPa})$ and impact work at $-20^{\circ} \mathrm{C}(>8 \mathrm{~J})$ in as cast state as a function of $\mathrm{Si}, \mathrm{Cu}, \mathrm{Ni}$ and $\mathrm{Co}$ content, optimum is accomplished in the light grey areas

The separately cast optimum alloy with minimal element input $(1.6 \% \mathrm{Si}, 0.2 \% \mathrm{Cu}, 0 \% \mathrm{Ni}$, $0 \mathrm{wt} \% \mathrm{Co}$ ) results in a yield strength of $242 \pm 1 \mathrm{MPa}$ and an impact work of $8 \pm 1 \mathrm{~J}$ at $-20{ }^{\circ} \mathrm{C}$. The yield strength differs by $17 \mathrm{MPa}$ from the value predicted but regarding the deviations in the underlying results from N1-11 (see Tab. 4) this is an acceptable accuracy. Therefore, this optimum composition alloy proves the DoE to be generally correct and it fulfils the requirements of the new developed alloy with minimal alloying input.
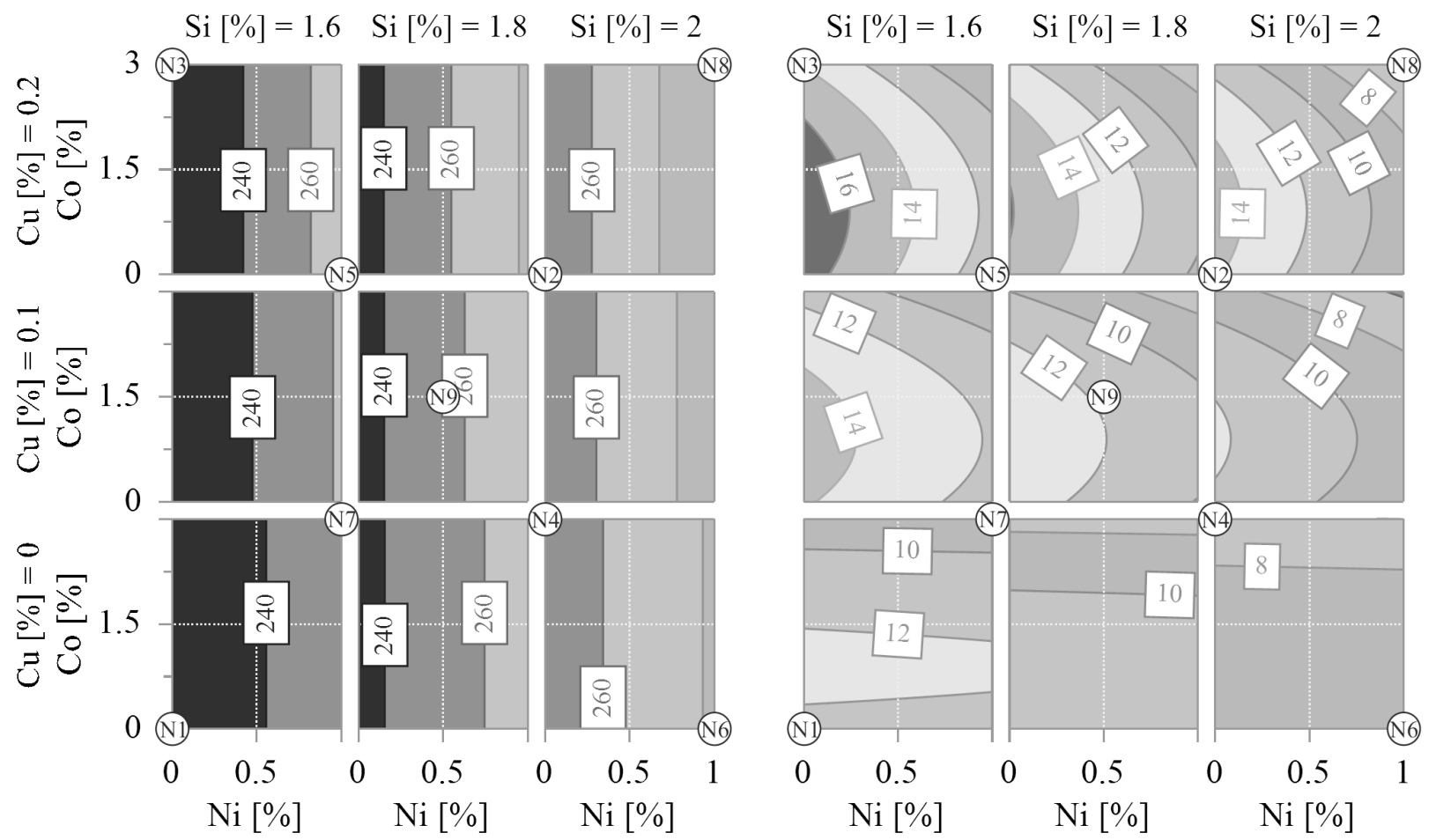

Figure 4: Modified interpolation approach of yield strength (left) and impact work at $-20{ }^{\circ} \mathrm{C}$ (right) in ferritic state as a function of $\mathrm{Si}, \mathrm{Cu}, \mathrm{Ni}$ and $\mathrm{Co}$ content 
The same interpolation approach has been applied to the data gained from the heat treated ferritic samples. The results are depicted in Fig. 4 and 5. In ferritic state the yield strength is, in fact, much lower (Tab. 4, Fig. 4) than in as cast state (Tab. 4, Fig. 2) due to the much softer ferritic matrix. However, the gradient of the yield strength does not change, as the factors used here are the same as in as cast state. The impact work on the other hand is much higher in total and covers a higher span of values. It shows that the ferritic matrix has a completely positive influence on impact work - as expected from literature - and the influence of nickel can be clearly seen as it lowers the impact work with higher mass fraction.

Compared to the as cast state (Fig. 3) the sweet spot plot for the ferritic samples does look different (Fig. 5). The former optimum has vanished and was replaced by the light grey areas with higher nickel content. The impact work criterion of $8 \mathrm{~J}$ is accomplished over the whole element spectrum considered. In the dark areas it is the yield strength condition which is not fulfilled as the matrix is too soft. This means that for heat treated samples nickel or a higher silicon/copper content is needed to strengthen the matrix.

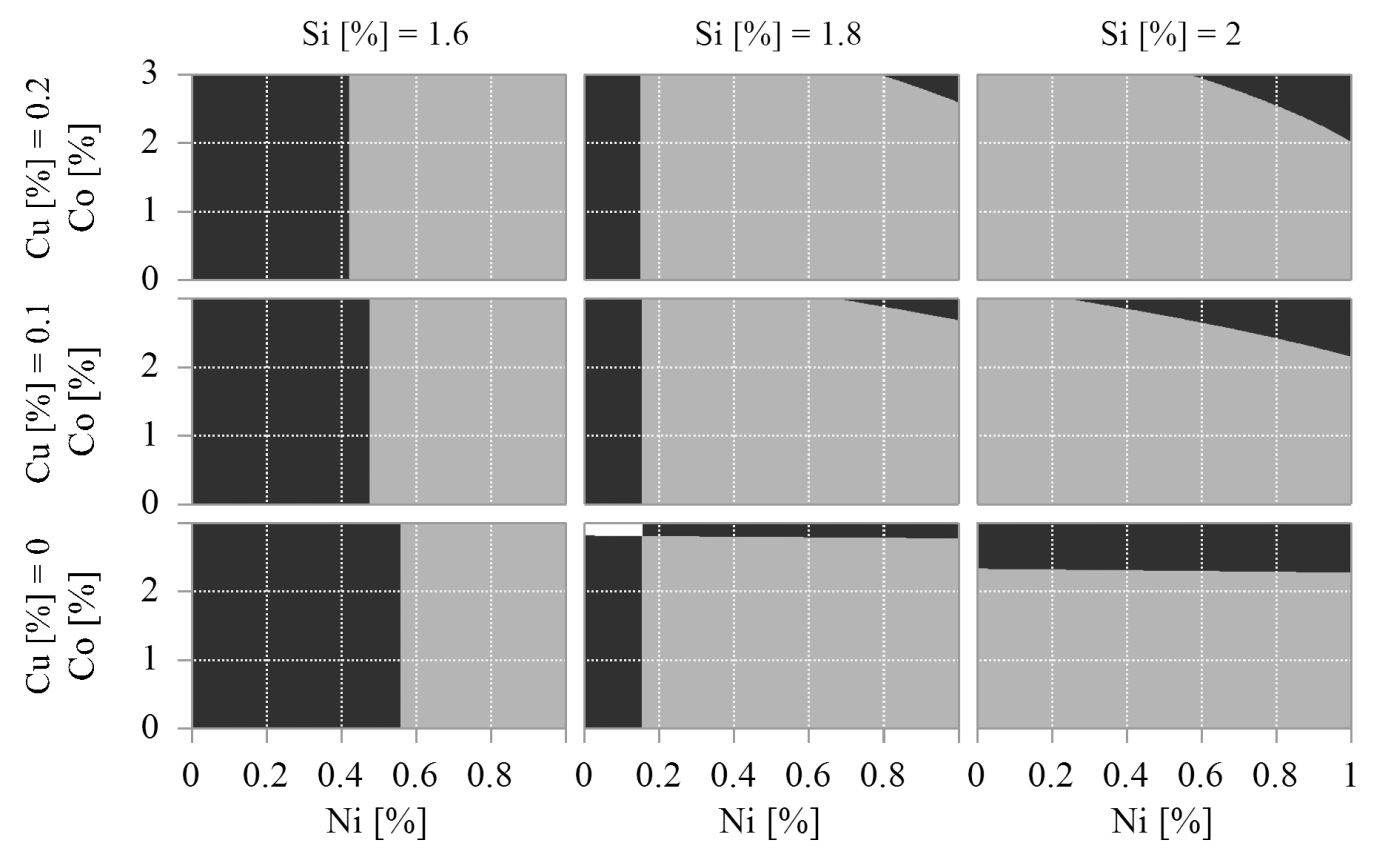

Figure 5: Sweet spot plot of yield strength $(>240 \mathrm{MPa})$ and impact work at $-20^{\circ} \mathrm{C}(>8 \mathrm{~J})$ in as

ferritic state as a function of $\mathrm{Si}, \mathrm{Cu}, \mathrm{Ni}$ and $\mathrm{Co}$ content, optimum is accomplished in the light grey areas

\section{Conclusions}

A design of experiments has been performed with a fractional factorial design and it has proven to be a useful tool for alloy design. The DoE model sweet spot plot agrees with literature relating to the impact of elements considered in this study. The difference between ferritic and as cast samples becomes apparent in the decrease of yield strength and increase of impact work with rising ferrite content. From this it can be concluded that for thick-walled castings with imperfect ferrite formation a low nickel/silicon content is still sufficient to accomplish the desired improvements. The final composition with preferably low element content for thick-walled castings would be $1.6 \mathrm{wt} \% \mathrm{Si}, 0.2 \mathrm{wt} \% \mathrm{Cu}, 0 \mathrm{wt} \% \mathrm{Ni}$ and $0 \mathrm{wt} \%$ Co whereas nickel and cobalt ratio can be increased according to Fig. 3. The cast validation alloy proved the model to be correct for developing new alloys for thick-walled castings.

\section{Acknowledgements}

We wish to thank our partners for the enlightening and excellent cooperation: Elkem, Enercon $\mathrm{GmbH}$, Georg Fischer AG, Heger Guss GmbH, Magma Gießereitechnologie GmbH, MAN SE, 
Procast Guss GmbH, ZF Friedrichshafen AG. In addition, we are very thankful for the financial support of the Federal Ministry of Education and research.

\section{References}

[1] R. Deike, Einfluss von Spurenelementen auf die eutektische Erstarrung und die eutektoide Umwandlung von Gußeisen, Giesserei 86 (1999) 175-182.

[2] R.C. Voigt, C.R. Loper Jr., Bildung der Grundmasse von Gusseisen mit Kugelgraphit, Giesserei-Praxis 22 (1990) 374-381.

[3] J. Lacaze, A. Boudot, V. Gerval, D. Oquab, H. Santos, The Role of Manganese and Copper in the Eutectoid Transformation of Spheroidal Graphite Cast Iron, Metall. Mater. Trans. A 28A (1997) 2015-2025.

[4] Deutsches Kupfer-Institut e. V., Kupfer in Gußeisen, Deutsches Kupfer-Institut e. V., BerlinCharlottenburg, 1962.

[5] T. Kanno, T. Kikuchi, I. Kang, Effect of Alloying Elements on the Eutectic Temperatures in Cast Iron, AFS Transactions 113 (2005) 825-833.

[6] J.F. Janoak, R.B. Gundlach, Hinweise zur modernen Legierungstechnik bei Gußeisen mit Lamellengraphit, Giesserei-Praxis (1983) 223-242.

[7] M. Schrumpf, Einfluss verschiedener Impfmittel auf die Zähigkeit von unlegiertem Gusseisen mit Kugelgraphit, konstruieren + giessen 32 (2007) 12-17.

[8] R.A. Gonzaga, Influence of ferrite and pearlite content on mechanical properties of ductile cast irons, Mater. Sci. Eng. A 567 (2013) 1-8.

[9] K.-F. Nilsson, V. Vokál, Analysis of ductile cast iron tensile tests to relate ductility variation to casting defects and material microstructure, Mater. Sci. Eng. A 502 (2009) 54-63.

[10] P. Čanžar, Z. Tonković, J. Kodvanj, Microstructure influence on fatigue behaviour of nodular cast iron, Mater. Sci. Eng. A 556 (2012) 88-99.

[11] H. Berns, W. Theisen, Eisenwerkstoffe: Stahl und Gusseisen, 3rd ed., Springer, Berlin, New York, 2006.

[12] A. de Sy, Die Anwendung von Kupfer bei Gußeisen mit Lamellengraphit, Giesserei 51 (1964) $25-32$.

[13] J. Verelst, A. de Sy, Der Einfluß einiger Elemente auf die Kugelbildung in Gußeisen, Giesserei 43 (1956) 305-315.

[14] J. Sertucha, P. Larrañaga, J. Lacaze, M. Insausti, Experimental Investigation on the Effect of Copper Upon Eutectoid Transformation of As-Cast and Austenitized Spheroidal Graphite Cast Iron, Int. J. Metalcast. 4 (2010) 51-58.

[15] G.S. Cho, K.H. Choe, K.W. Lee, A. Ikenaga, Effects of alloying elements on the microstructures and mechanical properties of heavy section ductile cast iron, J Mater Sci Technol 23 (2007) 97-101.

[16] Y. Kawano, S. Yamamoto, N. Inoyama, Influence of Nickel and Copper on Impact Resistant Properties of Ferritic-Annealed Spheroidal Graphite Cast Iron, J. Jpn. F. Soc. (Journal of Japan Foundrymen's Society) 59 (1987) 531-535.

[17] E.K. Modl, Kobaltlegiertes Gußeisen mit Kugelgraphit, Giesserei 55 (1968) 244-251.

[18] W.C. Leslie, Iron and Its Dilute Substitutional Solid Solutions, Metall. Trans. (Metallurgical Transactions) 3 (1972) 5-36.

[19] C.-H. Hsu, M.-L. Chen, C.-J. Hu, Microstructure and mechanical properties of 4\% cobalt and nickel alloyed ductile irons, Mater. Sci. Eng. A 444 (2007) 339-346.

[20] W. Thury, R. Hummer, E. Nechtelberger, Der Einfluß von Kobalt, Nickel und Kupfer auf das Gefüge und die mechanischen Eigenschaften von Gußeisen mit Kugelgraphit, Giesserei-Praxis (1967) 273-279.

[21] E. Wüller, Einfluss von Legierungselementen auf die Gefügeausbildung und mechanische Eigenschaften von Gusseisen mit Kugelgraphit. Dissertation, Giesserei Institut der RWTH Aachen, Aachen, 2015. 